\title{
Repetibilidade e importância de caracteres para avaliação de coleção ativa de germoplasma de batata
}

\author{
Giovani O da Silva ${ }^{1}$; Arione S Pereira ${ }^{2}$; Caroline M Castro²; Velci Q Souza ${ }^{3}$; Fernando IF Carvalho ${ }^{3}$; \\ Roberto Fritsche Neto ${ }^{4}$ \\ ${ }^{1}$ Embrapa Hortaliças, C. Postal: 218, 70351-970 Brasília-DF; ²Embrapa Clima Temperado, C. Postal 403, 96001-970 Pelotas-RS; ${ }^{3} \mathrm{UF}-$ \\ PEL/FAEM, C. Postal 354, 96010-900 Pelotas-RS; Pós Graduando em Agronomia, ESALQ; olegario@cnph.embrapa.br
}

\begin{abstract}
RESUMO
Como a base genética da batata cultivada Solanum tuberosum L. é estreita, torna-se importante a utilização do germoplasma existente nos programas de melhoramento, associada a um eficiente método de caracterização. O objetivo foi verificar a repetibilidade, o número de avaliações necessárias e a importância relativa de caracteres fenotípicos na caracterização de uma coleção ativa de germoplasma de batata. Um conjunto de 77 cultivares e clones elite de batata foi cultivado no campo experimental da Embrapa Clima Temperado, nas primaveras de 1999, 2000, 2001, 2002 e 2003, em parcelas de fileira simples de 15 plantas, espaçadas de $0,30 \times 0,80 \mathrm{~m}$, dentro e entre fileiras, respectivamente. Foram avaliados 31 caracteres nas plantas e nos tubérculos, os quais fazem parte dos descritores mínimos da batata. Os dados foram submetidos à análise de variância, de repetibilidade e de importância de caracteres. Concluiu-se que os caracteres com maior importância na caracterização do germoplasma avaliado são pigmentação da haste e intensidade de coloração da base do broto, tanto pela porcentagem de contribuição quanto pela repetibilidade da expressão nos diferentes anos de cultivo, refletindo no reduzido número de avaliações necessárias. Os caracteres coalescência da folha e pigmentação da nervura, presença de asas, tipo de folhagem, inserção da folha, largura dos folíolos, tamanho dos folíolos, cor da película, freqüência de flores, pubescência da base do broto, pigmentação do pedúnculo e pigmentação externa da corola, aspecto do ápice e aspereza da película, por apresentarem menores repetibilidades e/ou menores contribuições para a dissimilaridade, podem receber menos ênfase nas avaliações.
\end{abstract}

Palavras-chave: Solanum tuberosum L., contribuição relativa, caracteres morfológicos.

\begin{abstract}
Repeatability and the importance of characters in the evaluation of a potato active germplasm collection

As the genetic base of the cultivated potato (Solanum tuberosum L.) is narrow, it is important to use the existing germplasm in the breeding programs, associated with an efficient characterization method. We verified the repeatability, the necessary number of evaluations and the relative importance of phenotypic characters in the characterization of an active potato germplasm bank. A group of 77 potato cultivars and elite clones was cultivated in the experimental field of Embrapa Clima Temperado, on spring seasons of the years 1999, 2000, 2001, 2002 and 2003. The plots consisted of a single row of 15 plants, spaced $0.30 \times 0.80 \mathrm{~m}$, within and between rows, respectively. Thirty-three plant and tuber descriptors characters were evaluated. The data were submitted to the analysis of variance, repeatability and importance of characters. Stem pigmentation and color intensity of the sprout base are the more important characters to characterize the potato germplasm, either by the percentage of contribution or by the repeatability of the expression in the various growing years, reflecting in a reduced number of necessary evaluations. The characters leaf coalescence and vein pigmentation, presence of wings, foliage type, leaf insertion, leaflet width, leaflet size, skin color, flower frequency, pubescence of sprout base, peduncle and external corolla pigmentation, apex aspect, and skin roughness showed reduced repeatability and/or small contribution for the dissimilarity. Therefore they should receive less emphasis in the evaluations.
\end{abstract}

Keywords: Solanum tuberosum L., relative contribution, morphologic characters.

\section{(Recebido para publicação em 14 de março de 2008; aceito em 10 de junho de 2009)} (Received in March 14, 2008; accepted in June 10, 2009)

E $m$ batata, o desafio de identificar genótipos com caracteres superiores é dificultado devido às diferenças entre as cultivares existentes, atualmente, serem cada vez menores e o número de caracteres que necessitam ser considerados cada vez maiores. Isto se deve, em grande parte, ao estreitamento da base genética da cultura (Hawkes, 1978). Portanto, o melhoramento, principalmente em longo prazo, tem que ser baseado em estratégias que possibilitem maximizar a base genética da população de melhoramento.
Nos bancos de germoplasma, a correta caracterização e avaliação dos acessos presentes é de fundamental importância (Wetzel et al., 2007), podendo ser realizada com a utilização dos descritores de cada espécie. Estes descritores possibilitam diferenciar genótipos de acordo com uma série de características, algumas com maior e outras com menor grau de diferenciação. Estudos quantificando este poder de diferenciação são importantes na tomada de decisão sobre a manutenção de características das listas de descrito- res; ou na verificação de descritores aos quais deve-se dar maior importância no momento da caracterização. A utilização da análise da importância de caracteres de Singh (1981) possibilita classificar as variáveis estudadas de acordo com sua contribuição particular para a divergência genética total, permitindo selecionar aquelas com maior contribuição relativa.

Diversas características variam quanto ao número ideal de medidas que devem ser efetuadas para se ter confiabilidade nos resultados. Isso pode 
ser avaliado por meio do coeficiente de repetibilidade da característica. O coeficiente de repetibilidade é possível de ser obtido quando a medição de um determinado caráter é feita repetidas vezes em um mesmo indivíduo no tempo ou no espaço (Cruz \& Regazzi, 2001).

Valores altos de estimativas de repetibilidade para determinado caráter indicam que é viável predizer o valor real do indivíduo utilizando-se um número relativamente pequeno de medições, sendo que ocorre o inverso quando a repetibilidade é baixa (Cargnelutti et al., 2004). De acordo com Falconer (1981), quando várias medidas de um mesmo caráter são feitas em cada indivíduo, a variância fenotípica poderá ser parcelada, servindo para quantificar o ganho em precisão, pela repetição das medidas, e esclarecer a natureza da variação causada pelo ambiente. O coeficiente de repetibilidade determina o máximo valor de herdabilidade para um determinado caráter (Cruz \& Regazzi, 2001).

Por meio do coeficiente de repetibilidade pode-se determinar o número de medições necessárias em indivíduos, para se predizer o valor real dos mesmos, com certo grau de probabilidade $\left(\mathrm{R}^{2}\right)$ que representa a porcentagem de certeza da predição do valor real dos indivíduos selecionados com base em " $n$ " medições, pois, é simples de ser estimado, não exigindo cruzamentos controlados e estudo de progênies (Costa, 2003). Além disso, caso estas características sejam de importância para o melhoramento, estas informações podem ser também úteis na identificação do recurso genético para ser utilizado em cruzamentos.

Considerando a escassez de estudos semelhantes com esta cultura na literatura, o objetivo foi verificar a repetibilidade, o número de avaliações necessárias e a importância relativa de caracteres fenotípicos na caracterização de uma coleção ativa de germoplasma de batata.

\section{MATERIAL E MÉTODOS}

Foi avaliado um conjunto de 77 cultivares e clones elite componentes da Coleção Ativa de Germoplasma da Embrapa Clima Temperado. Os genó- tipos foram cultivados nas primaveras de 1999, 2000, 2001, 2002 e 2003 em campo da Embrapa Clima Temperado, em parcelas de 15 plantas, com repetição realizada no tempo, e delineamento completamente casualizado, espaçadas $0,30 \mathrm{~m}$ entre plantas e $0,80 \mathrm{~m}$ entre fileiras. Manejadas com os tratos culturais para cultivo a campo, os tubérculos foram colhidos aproximadamente 110 dias após o plantio. Foram avaliados 31 caracteres nas plantas e nos tubérculos, estes fazendo parte dos descritores mínimos da batata: formato do broto, intensidade de coloração da base do broto, pubescência da base do broto, aspecto do ápice do broto, intensidade de primórdios radiculares do broto, comprimento da brotação lateral do broto, tipo de planta em relação à folhagem, hábito de crescimento da planta, pigmentação da haste da planta, asas da planta, inserção das folhas, fechamento das folhas, pigmentação na nervura principal das folhas, tamanho dos folíolos, largura dos folíolos, coalescência dos folíolos, ondulação das bordas dos folíolos, frequência de folíolos secundários, frequência de flores na inflorescência, comprimento do pedúnculo floral, pigmentação do pedúnculo floral, intensidade de pigmentação na parte interna da corola, pigmentação na parte externa da corola, freqüência de frutos, desenvolvimento, ciclo vegetativo, formato de tubérculos, profundidade de olhos, aspereza de película, cor de película e cor de polpa, avaliados segundo notas especificadas em Brasil (1997).

Os dados fenotípicos após transformados $(x+0,50)^{1 / 2}$, para possibilitar a normalidade e verificada a homogeneidade de variância foram submetidos à análise de variância considerando ano como repetição, objetivando verificar a efetividade dos caracteres em diferenciar os genótipos nos sucessivos anos de cultivo; procedeu-se ainda análise de repetibilidade e número de avaliações necessárias para caracterizar os genótipos, bem como análise de importância dos caracteres na discriminação da variação fenotípica, com utilização do programa GENES (Cruz, 2001).

\section{RESULTADOS E DISCUSSÃO}

Foi observada variabilidade signifi- cativa em todos os caracteres para diferenciar os genótipos estudados. Verificase que, com exceção de pigmentação da nervura, tamanho dos folíolos e largura dos folíolos, todos os demais caracteres com significância para o efeito de ano de cultivo, indicando que para a maioria dos caracteres os acessos foram classificados de forma diferente nos sucessivos anos, devido a variações de ambiente que ocorrem nos diferentes anos.

Observou-se coeficientes de repetibilidade (Tabela 1) com valores muito reduzidos para aspecto do ápice, coalescência da folha, pigmentação da nervura e aspereza da película, valores abaixo de 0,30 . O valor reduzido de repetibilidade para aspereza de película é discordante dos resultados de Love et al. (1997) que verificaram elevada herdabilidade para esse caráter, no entanto esses autores utilizaram genótipos que se caracterizaram por apresentar película extremamente áspera, diferentemente deste trabalho onde muitos dos genótipos foram selecionados para película lisa. Para estes caracteres seria necessário efetuar entre 8 a 12,4 avaliações para ter porcentagem de certeza da predição do valor real dos indivíduos selecionados $\left(\mathrm{R}^{2}\right)$ de 0,80 (Tabela 2 e 3), além de contribuírem com pequena porcentagem relativa para a distinção dos genótipos avaliados (Tabela 1).

Coeficiente de repetibilidade acima de 0,60 , foi verificado para os caracteres hábito de crescimento, pigmentação externa da corola, ciclo vegetativo, formato de tubérculo, cor da polpa, intensidade de coloração interna da corola, pigmentação da haste e intensidade de coloração da base do broto; sendo que os dois últimos foram maiores que 0,70. A alta repetibilidade verificada para formato de tubérculo é concordante com o trabalho de Love et al. (1997) e Pinto (1999) que verificaram alto coeficiente de herdabilidade para esse caráter.

Intensidade de coloração da base do broto e pigmentação da haste além de apresentarem os maiores valores de repetibilidade possuem também contribuição relativa superior para a divergência genética, com valores acima de 10\% (Tabela 1). O comprimento do pedúnculo também contribuiu com mais de $10 \%$ para a distinção dos genótipos, 
Tabela 1. Análise de repetibilidade e contribuição relativa de 33 descritores mínimos de batata para a divergência de 77 genótipos avaliados durante cinco culturas de primavera (repeatability and relative contribution analysis of 33 minimum potato derscriptors to the divergence of 77 genotypes evaluated in five spring cultivations). Pelotas, Embrapa Clima Temperado, 2006.

\begin{tabular}{lcc}
\hline Caráter & Repetibilidade & Contribuição \\
& & $\mathbf{( \% )}$ \\
\hline Aspecto do ápice & 0,24 & 1,65 \\
Coalescência da folha & 0,27 & 0,14 \\
Pigmentação da nervura & 0,29 & 0,33 \\
Aspereza da película & 0,29 & 0,94 \\
Ondulação das bordas & 0,33 & 1,87 \\
Presença de asas & 0,35 & 0,41 \\
Tipo de folhagem & 0,36 & 0,59 \\
Inserção da folha & 0,37 & 0,25 \\
Fechamento da folha & 0,37 & 1,26 \\
Largura dos folíolos & 0,39 & 0,87 \\
Tamanho dos folíolos & 0,39 & 0,97 \\
Comprimento da brotação lateral & 0,40 & 3,50 \\
Profundidade de olhos & 0,40 & 1,08 \\
Cor da película & 0,41 & 0,25 \\
Freqüência de folíolos secundários & 0,41 & 1,64 \\
Freqüência de flores & 0,45 & 0,52 \\
Comprimento do pedúnculo & 0,46 & 13,03 \\
Pubescência da base do broto & 0,47 & 0,90 \\
Intensidade de primórdios radiculares & 0,48 & 2,08 \\
Pigmentação do pedúnculo & 0,51 & 0,74 \\
Desenvolvimento da planta & 0,55 & 3,84 \\
Formato do broto & 0,56 & 6,51 \\
Freqüência de frutos & 0,57 & 6,97 \\
Hábito de crescimento & 0,60 & 3,27 \\
Pigmentação externa da corola & 0,60 & 0,80 \\
Ciclo vegetativo & 0,60 & 2,68 \\
Formato de tubérculo & 0,60 & 2,60 \\
Cor da polpa & 0,63 & 2,14 \\
Intensidade de coloração interna da & 0,67 & 3,87 \\
corola & 0,74 & 10,01 \\
Pigmentação da haste & 0,78 & 15,81 \\
Intensidade de coloração da base do broto & & \\
\hline
\end{tabular}

${ }^{1}$ Contribuição relativa dos caracteres [SINGH (1981)], pelo quadrado da distância Euclidiana (character relative contribution SINGH (1981), by Euclidiana distance square).

porém a repetibilidade foi de 0,46 . Os caracteres coalescência da folha, pigmentação da nervura, presença de asas, tipo de folhagem, inserção da folha, largura dos folíolos, tamanho dos folíolos, cor da película, frequência de flores, pubescência da base do broto, pigmentação do pedúnculo e pigmentação externa da corola, tiveram contribuição menor (abaixo de 1\%), sendo que o último caráter, apesar de apresentar menor contribuição, foi um dos caracteres com maior repetibilidade, o que enfatiza a alta similaridade do germoplasma avaliado para este caráter (Tabela 1). A menor contribuição relativa de coloração de película é discordante dos resultados de Luthra et al. (2005) que, avaliando 20 caracteres de planta e de tubérculo, observaram grande contribuição deste caráter para a divergência total. Esses mesmos autores encontraram menor contribuição para tamanho e largura dos folíolos, formato de tubérculo e profundidade de olhos, $o$ que concorda com os resultados encontrados neste trabalho.

Em relação ao número de avaliações necessárias para a caracterização, verifica-se que as cinco avaliações efetuadas são suficientes na caracterização dos genótipos com $80 \%$ de coeficiente de determinação para hábito de crescimento, pigmentação da haste, freqüência de flores, pigmentação do pedúnculo, intensidade de coloração interna da corola, pigmentação externa da corola, frequência de frutos, desenvolvimento da planta, ciclo vegetativo, formato do broto, intensidade de coloração da base do broto, pubescência da base do broto, intensidade de primórdios radiculares, formato de tubérculo e cor da polpa. Para pigmentação da haste, intensidade de coloração interna da corola e intensidade de coloração da base do broto, cinco avaliações caracterizaram os genótipos com $90 \%$ de coeficiente de determinação (Tabela 2 e 3 ).

Desta forma, os caracteres com maior importância na caracterização do germoplasma avaliado são pigmentação da haste e intensidade de coloração da base do broto, tanto pela porcentagem de contribuição quanto pela repetibilidade da expressão nos diferentes cultivos, refletindo no reduzido número avaliações necessárias para a caracterização. Já os caracteres coalescência da folha e pigmentação da nervura, presença de asas, tipo de folhagem, inserção da folha, largura dos folíolos, tamanho dos folíolos, cor da película, freqüência de flores, pubescência da base do broto, pigmentação do pedúnculo e pigmentação externa da corola, aspecto do ápice e aspereza da película, por apresentar menor repetibilidade e/ou menor contribuição para a dissimilaridade, podese dar menor ênfase no momento das avaliações.

\section{REFERÊNCIAS}

BRASIL. 1997. Decreto $\mathrm{n}^{\circ} 2.366$, de 5 de 
Tabela 2. Número de avaliações necessárias para descritores mínimos de batata ${ }^{1}$, com diferentes coeficientes de determinação $\left(\mathrm{R}^{2}\right)$ (necessary number of evaluations to minimum potato descriptors ${ }^{1}$, with distinct determination coefficients $\left(\mathrm{R}^{2}\right)$ ). Pelotas, Embrapa Clima Temperado, 2006.

\begin{tabular}{ccccccc}
\hline $\mathbf{R}^{\mathbf{2}}$ & Folhg $^{\mathbf{1}}$ & HC & PgH & Asas & Inser & FecF \\
\hline 0,80 & 6,98 & 2,80 & 1,41 & 7,31 & 6,82 & 6,82 \\
0,85 & 9,89 & 3,97 & 2,00 & 10,36 & 9,67 & 9,67 \\
0,90 & 15,72 & 6,31 & 3,18 & 16,45 & 15,36 & 15,36 \\
0,95 & 33,18 & 13,32 & 6,72 & 34,73 & 32,43 & 32,43 \\
\hline & FFSec & FreFl & ComP & PigP & IntCInt & IntCr \\
\hline 0,80 & 5,67 & 4,86 & 4,70 & 3,80 & 1,10 & 1,99 \\
0,85 & 8,03 & 6,88 & 6,66 & 5,39 & 1,56 & 2,82 \\
0,90 & 12,75 & 10,93 & 10,58 & 8,56 & 2,48 & 4,48 \\
0,95 & 26,92 & 23,07 & 22,35 & 18,07 & 5,24 & 9,47 \\
\hline & Pubsc & Aspecto & IntPrim & ComBr & - & - \\
\hline 0,80 & 4,46 & 12,40 & 4,35 & 6,12 & - & - \\
0,85 & 6,31 & 17,56 & 6,16 & 8,66 & - & - \\
0,90 & 10,03 & 27,89 & 9,78 & 13,76 & - & - \\
0,95 & 21,17 & 58,88 & 20,64 & 29,05 & - & - \\
\hline
\end{tabular}

${ }^{1}$ Folhg = tipo de folhagem; $\mathrm{HC}=$ hábito de crescimento; $\mathrm{PgH}=$ pigmentação da haste; Asas= presença de asas; Inser $=$ inserção da folha; $\mathrm{FecF}=$ fechamento da folha; $\mathrm{FFSec}=$ freqüência de folíolos secundários; $\mathrm{FreFl}=$ freqüência de flores; $\mathrm{ComP}=$ comprimento do pedúnculo; $\mathrm{PigP}=$ pigmentação do pedúnculo; IntCInt= intensidade de coloração interna da corola; $\mathrm{IntCr}=$ intensidade de coloração da base do broto; $\mathrm{Pubsc}=$ pubescência da base do broto; Aspecto= aspecto do ápice; IntPrim= intensidade de primórdios radiculares; $\mathrm{ComBr}=$ comprimento da brotação lateral ( ${ }^{1} \mathrm{Folhg}=$ foliage type; $\mathrm{HC}=$ growth habit; $\mathrm{PgH}=$ stem pigmentation; Asas= wings presence; Inser= leaf insertion; $\mathrm{FecF}=$ leaf closing; $\mathrm{FFSec}=$ secundary leaflets frequency; $\mathrm{FreFl}=$ flower frequency; $\mathrm{ComP}=$ stalk lenght; $\mathrm{PigP}=$ stalk pigmentation; $\mathrm{IntCInt}=$ intensity of internal corolla coloration; $\mathrm{IntCr}=$ intensity of the base sprout coloration; $\mathrm{Pubsc}=$ base sprout pubescency; Aspecto= apex aspect; IntPrim= root primordies intensity; ComBr= length of the lateral sprout).

Tabela 3. Número de avaliações necessárias para descritores mínimos de batata ${ }^{1}$, com diferentes coeficientes de determinação $\left(\mathrm{R}^{2}\right)$ (necessary number of evaluations to minimun potato descriptors ${ }^{1}$, with distinct determination coefficients $\left(\mathrm{R}^{2}\right)$ ). Pelotas, Embrapa Clima Temperado, 2006.

\begin{tabular}{cccccc}
\hline $\mathbf{R}^{\mathbf{2}}$ & PgN $^{\mathbf{1}}$ & TamF & LagF & CoaFo & OndF \\
\hline 0,80 & 9,51 & 6,23 & 6,25 & 10,99 & 7,98 \\
0,85 & 13,47 & 8,82 & 8,85 & 15,56 & 11,31 \\
0,90 & 21,40 & 14,01 & 14,05 & 24,72 & 17,96 \\
0,95 & 45,19 & 29,59 & 29,67 & 52,18 & 37,91 \\
\hline & PigExt & Frutos & Des & Ciclo & Fbroto \\
\hline 0,80 & 2,78 & 2,98 & 3,27 & 2,72 & 3,16 \\
0,85 & 3,94 & 4,23 & 4,63 & 3,86 & 4,48 \\
0,90 & 6,26 & 6,71 & 7,36 & 6,13 & 7,11 \\
0,95 & 13,22 & 14,17 & 15,54 & 12,93 & 15,01 \\
\hline & FTub & Olhos & CrPel & AspPel & CrPolp \\
\hline 0,80 & 2,68 & 5,90 & 5,71 & 8,10 & 2,35 \\
0,85 & 3,80 & 8,35 & 8,09 & 11,47 & 3,34 \\
0,90 & 6,04 & 13,27 & 12,85 & 18,22 & 5,30 \\
0,95 & 12,75 & 28,01 & 27,14 & 38,47 & 11,18 \\
\hline
\end{tabular}

${ }^{1} \mathrm{PgN}=$ pigmentação da nervura; TamF= tamanho dos folíolos; $\mathrm{LagF}=$ largura dos folíolos; $\mathrm{CoaFo}=$ coalescência da folha; $\mathrm{OndF}=$ ondulação das bordas; PigExt= pigmentação externa da corola; Frutos $=$ freqüência de frutos; $\mathrm{Des}=$ desenvolvimento da planta; $\mathrm{Ciclo}=$ ciclo vegetativo; Fbroto = formato do broto; FTub= formato do tubérculo; Olhos= profundidade de olhos; $\mathrm{CrPel}=$ cor da película; $\mathrm{AspPel}=$ aspereza da película; $\mathrm{CrPolp}=$ cor da polpa $\left({ }^{1} \mathrm{PgN}=\right.$ rib pigmentation; TamF= leaflet lenght; $\mathrm{LagF}=$ leaflet width; $\mathrm{CoaFo}=$ leaf coalescence; $\mathrm{OndF}=$ border ondulation; PigExt $=$ external corolla pigmentation; Frutos $=$ fruits frequency; Des= plant growth Ciclo= vegetative cycle; Fbroto= sprout format; FTub= tuber format; Olhos= eye deepness; $\mathrm{CrPel}=$ skin color; $\mathrm{AspPel}=$ skin roughness; $\mathrm{CrPolp}=$ pulp color). novembro de 1997. Regulamenta a proteção de cultivares e os descritores das primeiras oito espécies que serão protegidas: algodão, arroz, batata, feijão, milho, soja, sorgo e trigo. Biotecnologia Ciência \& Desenvolvimento 1: 23-32.

CARGNELUTTI FILHO A; CASTILHOS ZMS. 2004. Análise de repetibilidade de caracteres forrageiros de genótipos de Panicum maximum, avaliados com e sem restrição solar. Ciência Rural 34: 723-729.

COSTA JG. 2003. Estimativas de repetibilidade de alguns caracteres de produção em Mangueira. Ciência Rural 33: 263-266.

CRUZ CD. 2001. Programa Genes: Aplicativo computacional em genética e estatística. Viçosa: UFV, 648 p.

CRUZ CD; REGAZZI AJ. 2001. Métodos biométricos aplicados ao melhoramento genético. Viçosa: UFV, $390 \mathrm{p}$.

FALCONER DS. 1981. Introdução à genética quantitativa. Viçosa: UFV, 279 p.

HAWKES JG. 1978. History of the potato. In: Harris PM. The potato crop: The scientific basis for improvement, London: Chapman \& Hall, 1-14.

LOVE SL; WERNER BK; PAVEK JJ. 1997. Selection for individual traits in the early generations of a potato breeding program dedicated to producing cultivars with tubers having long shape and russet skin. American Potato Journal 74: 199-213.

LUTHRA SK; Gopal J; Sharma PC. 2005. Genetic divergence and its relationship with heterosis in potato. American Potato Journal 32: 37-42.

PINTO CAB. 1999. Melhoramento genético de batata. Informe Agropecuário UFLA. 20: 120-128.

SINGH D. 1981. The relative importance of characters affecting genetic divergence. The Indian Journal of Genetics and Plant Breeding 41: 237-245.

WETZEL MMVS; FERREIRA FR. 2007. Sistema de curadorias de germoplasma. In: Recursos Genéticos Vegetais, NASS LL. Embrapa, $858 \mathrm{p}$. 